\title{
E Gendered Discourse in the Political Behavior 三 of Adolescents
}

\author{
CINDY SIMON ROSENTHAL, JOCELYN JONES, JAMES A. ROSENTHAL, UNIVERSITY OF OKLAHOMA
}

\begin{abstract}
The roots of adult civic and political participation originate in pre-adult experiences (Verba et al. 1995) and high school extracurricular activities offer students opportunities to develop interpersonal and leadership skills. In this research, we ask whether adolescents also learn gendered norms of political discourse through extracurricular activities. This project assessed gender differences in participation at the 1999 Model United Nations of the Southwest (MUNSW) at the University of Oklahoma. Important differences in participation were observed in the number and character of speaking turns taken by male and female delegates. We find that contextual factors, such as the sex of the committee chair, the issue areas addressed by the committee, and the timing of the session in the conference significantly influence who participates in the discourse, but the percentage of female participants surprisingly does not. The character of the political discourse suggests norms dominated by masculinity.
\end{abstract}

C oncerned about the quality of political representation, a number of scholars have turned their attention to women's participation in the political discourse of state and national legislatures. Women's inclusion in public debate is important because women bring different experiences, attitudes, and resources to the political table (Tamerius 1995; Schlozman et al. 1995). Women's efforts, however, may be thwarted by the realities of institutional life. Kathlene (1995) finds, for example, that women may not be fully effective at promoting feminist policy because of gendered power dynamics present in legislatures.

A few studies have addressed the gendered nature of political discourse in legislative settings (Kathlene 1994, 1995; Mattei 1998; Hale 1999; Levy et al. 2001; Walsh 2002.) What is unclear from prior research is whether the gendered contours of political discourse are primarily due to institutional factors or mostly a product of gendered norms of behavior per se. In this research, we address this question by exploring adolescent behavior in a legislative simulation. We ask: Is gender discourse in this kind of extra-curricular activity highly masculinized? What effect, if any, do institutional factors have on discourse?

Many universities sponsor Model United Nations (MUN) simulations as an extracurricular activity for adolescents and young adults from middle school through college. These simulations provide an opportunity to view adolescent socialization to world politics and offer a quasi-experimental setting in which to examine how male and female adolescents engage in political discourse and experience political learning. In this project, we observe the University of Oklahoma's 1999 Model United Nations of the Southwest (MUNSW), where 382 adolescents and young adults

Political Research Quarterly, Vol. 56, No. 1 (March 2003): pp. 97-104 engaged in the process of acquiring skills of debate, negotiation, and coalition building. As Roberta S. Sigel (1989: 468) admonishes: ". . . inasmuch as we always maintain that political socialization is a process, it is imperative to collect process data. ... An ongoing process cannot be studied by such [retrospective] methods and even less by the administration of mass survey instruments. It must be studied by observing it as it progresses, i.e., in the field."

\section{Gender Discourse}

Turn-taking is a critical variable in political discourse. To speak in a political setting is the threshold activity required of a person to be seen, heard, and to represent oneself or others. In the context of a roleplay, participants are acting as policy representatives but absent the realities of electoral and cultural ties. In Pitkin's (1967) typology, they are literally "acting for." "Their role, the reason for labeling their job as 'representing,' is to speak for, act for, look after the interests of their respective groups"(116, emphasis added). Turns also are a key measure of gender power differences and expectations about the competence of participants in mixed-sex interaction. Reviewing 63 studies of the amount of talk by men and women in different groups, James and Drakich (1993: 300-01) conclude that "Differences in cultural expectations about the areas in which men and women are competent determine men's and women's actual performances and, consequently, the amount of talk."

A number of studies have focused on interruptions as a particular form of turn-taking, which are exceptions to conversational norms. Interruptions are an exertion of conversational dominance and control with men interrupting women more often than the reverse (Zimmerman and West 1975; Kollock, Blumstein, and Schwartz 1985; Lakoff 1990). Smith-Lovin and Brody (1989), however, argue that 
men and women make equal attempts at interruption, but men are more successful than women. Kathlene (1995) finds that men engage and interrupt other men more often than they do women but argues that male-male interaction marginalizes and excludes females in the legislative debate. On balance, the research on interruptions remains inconclusive and thus worthy of further study. In this study, we deal with a kind of parliamentary interruption-questions posed to speakers in the course of debate.

The literature on group interaction also suggests that men and women participate in substantively different ways. Men are more interested in accomplishing the task at hand and more likely to offer opinions and to talk in general (SmithLovin and Robinson 1992; see also Leet-Pellegrini 1980.) Conversely, women are more attentive to group solidarity and more likely to facilitate group discussion, to support the expression of opinions, and to agree with the suggestions of others within the group (Ridgeway and Johnson 1990).

Political science scholars have used discourse to understand the gendered nature of political institutions and processes. Kathlene (1994), in analyzing speaking behavior in Colorado state legislative committees, finds that women committee members not only speak and interrupt less often than men, but also engage later in the debate than do men. Similarly, Mattei (1998) finds that female witnesses before the U.S. Senate Judiciary Committee are not given equal access to political debate. In Hale's (1999) study of workplace communications among public service professionals and public administration/political science academicians, women specifically recount frustrations with men interrupting them.

The content of political discourse is also gendered. Kathlene(1995: 572) finds that female chairs use their leadership posts to facilitate discussions and include more voices while male chairs interject more of their own personal opinions and assert dominant verbal behavior such as cutting off speakers. Levy et al. (2001) and Walsh (2002) also conclude that congresswomen bring into debates different perspectives on issues.

A major concern in this line of research is the impact of the social composition of groups on individual behavior (Kanter 1977). Kathlene (1994: 179) explores the hypothesis that as women's numbers increase, women's participation in the political debate might increase as well. Studying committees with female membership ranging from 12 to 64 percent she finds that "men rather than women became significantly more vocal when women comprised greater proportions of the committee." At the MUNSW, unlike most elite political settings, female delegates comprise half of the entire event and thus are presumed to have all the advantages of "balanced" groups in which participation is most likely to be equal (Kanter 1977). But if pedagogical settings reward behavior regarded as "male" or "aggressive," then compositional advantages may be negated.

Based on the aforementioned work, we hypothesize that (1) female delegates will speak less and make fewer interruptions than their male peers because delegates have already internalized societal gender norms; (2) the content of the discourse will be more challenging and masculine in character because adolescents assume politics is a masculine domain; and (3) that the sex of the chair, the committee environment, and the percentage of females in attendance will affect the gendered dynamics of discourse.

\section{The Research Setting and Design}

This study examines discourse on global issues observed at the 1999 MUNSW. Delegates came from urban, suburban and rural schools in Kansas, Texas, New Mexico, and Oklahoma. On average, the schools had a demographic profile of: 76.3 percent Caucasian, 5.0 percent African American, 1.7 percent Asian, 4.1 percent Hispanic, and 13.0 percent Native American. The actual makeup of the delegates, however,was almost 90 percent Caucasian. ${ }^{1}$ Delegates were generally academically oriented; almost 80 percent voluntarily participated; and some competed on teams hand-picked or organized by teachers as part of their schools' gifted and talented curriculum.

Participating schools composed one or more teams representing individual nation(s) assigned on the basis of delegate qualifications and experience. Delegates researched their country, wrote appropriate resolutions, debated resolutions for the first three days in committees, and then convened in larger assemblies to debate resolutions approved by the individual committees. University students served as committee chairs, parliamentarians, and organizers.

We employed several research strategies. Research assistants coded data on delegate experience and backgrounds from application forms. Delegates also completed a pre-conference survey focusing on demographic characteristics, motivations, and media attentiveness in world affairs. Trained coder/observers monitored 97 hours of conference deliberations (67.5 percent of the entire conference and 85.4 percent of all committee sessions) for attendance, sex of the chair, and the frequency and nature of speech-making and various verbal interruptions. Coder/observers were assigned in pairs to committees with each recording different observations. ${ }^{2}$ The division of labor had the practical

\footnotetext{
${ }^{1} 1$ Demographic data on the schools were obtained from the Oklahoma Office of Accountability, Department of Education, www.schoolreportcard.org, and telephone interviews with individual coaches.

2 Coders were recruited from an upper division undergraduate political science course. Coders underwent two hours of training, including an orientation to parliamentary procedure and the particular discourse practices of the MUNSW. Coders completed written and videotaped exercises to identify turn-taking and record the eight specific speaking behaviors: disagreeing, attacking, proposing, agreeing, supporting, building, parliamentary and other. Coders were aware of the study's focus on gender differences in participation but did not know how specific speaking behaviors would be interpreted as challenging or nonchallenging. At the conclusion of the training, coders completed a pretest, coding a videotaped excerpt of a practice debate. The reliability of the pretest of coder identification of speaking turns and speaker sex was almost perfect (alpha $=.99$, mean inter-item correlation of coders scores $=.92$ ), and the reliability of coder identification of eight different speaking behaviors was also extremely high (alpha $=.99$, mean inter-item
} 
effect of simplifying coding responsibilities. During recesses in debate and between coding specific events, the coder/observers took notes on delegate interactions, the committee setting, and most and least active delegates.

Limitations of the study are the inability to measure length of speeches or to follow the behavior of specific delegates throughout the event. The number of delegates, the large size of the committees, and the event facilities made audio-taping impractical and thus transcripts impossible to develop. Since the length of speaking turns was regulated by the committee chairs, the variability in length (most less than two minutes) and the number of follow-up turns (one per speaker) was minimized. The field reports allowed tracking of the most active delegates between sessions, but did not provide a comprehensive, continuous accounting. These limitations do not detract from the ability to draw conclusions about the patterns of participation by delegates or to identify structural features of the event that influence participation.

\section{Participant Characteristics}

Females comprised 46.6 percent of the attendees and came with backgrounds, qualifications and experience almost identical to those of the male delegates. Based on analysis of delegate application forms, 45.7 percent of the females and 49.0 percent of the males had at least one year of prior Model UN experience. About one-third had debate experience (39.3 percent of the females and 32.0 percent of the males) or some other public speaking experience (33.5 percent of the females and 30.5 percent of the males). One significant difference in the backgrounds of the participants is age: female delegates were significantly younger (males $\overline{\mathrm{X}}$ $=15.9$ years, females $\bar{X}=15.1$ years, $p=.001$ ). Analyzed by grade cohorts, female participation peaks in the tenth grade and declines sharply in subsequent years. Male participation lags in the earlier grades, equals that of the girls in tenth grade, but continues to increase and exceed that of girls in eleventh and twelfth grades.

\section{The Data}

Based on the literature on gender discourse and gendered institutions, three main dependent variables are examined: (1) turn-taking (and type of turn) by speaker sex, (2) questions received by male and female speakers, and (3) the percentage of challenging turns taken in a speaking event. Turn-taking is essential if delegates are to "represent" their assigned countries, since delegates simulate only policy debate not other representational tasks. Furthermore, to get the most out of the learning experience, delegates

correlation of coders' scores $=.85$ ). In addition, each coder filed a field report identifying the delegates who emerged as committee leaders, describing differences in their speaking behavior compared to others, and describing the setting, room or proceedings that were important to the process of debate. After the conference, two readers systematically analyzed the content of the field reports, coding common themes in the reports. must try their hand at speaking. In total, 2082 turns were recorded throughout the event. Coders recorded turns that disagreed with, attacked, or proposed a course of action different from that of the previous speaker; coders also identified turns that agreed with, supported, or built upon a position made by a previous speaker. In the subsequent analysis, the three former turns were recoded as challenging behavior, and the three later turns were recoded as non-challenging. Parliamentary inquiries or turns that the coder could not clearly distinguish as challenging or non-challenging were coded as "other."

Second, questions received by each speaker provide a picture of delegate interactions. After delegates give a speech, they may be questioned by other delegates. Questions were coded as either challenging, helpful, or parliamentary. If MUNSW delegates differentiate their questioning by the sex of the speaker, we posit the pattern will reflect either engagement or exclusion. If female speakers are challenged more often than male speakers, the frequency of challenging behavior also may reflect perceptions about the status of the female speakers and opportunities for dominance.

Third, the tone of the discourse is examined for gendered dimensions. For the third dependent variable, the unit of analysis is a speaking event, meaning the entire sequence of turns (both challenging, non-challenging, and other) handled by a speaker once he or she makes a speech and then yields to questions, clarifications, or challenges from other delegates. The pattern of discourse resembles what Edelsky (1993) calls the exploration of the "floor"the institutional conditions under which a topic develops and participants interact. We posit more challenging events (i.e., a higher proportion of challenging turns) reflect masculine norms in debate.

Several key independent variables are controlled for in the analysis. First, coder/observers recorded the committee session, committee size, and gender composition. Reticence on the part of delegates was expected to diminish as the conference evolved. Attendance was taken at regular and frequent intervals throughout the conference, and the average proportion of females in attendance was calculated for each committee. Committee size is important because more women in the room increases the likelihood of nonverbal support among the females (Kathlene 1995; Swann 1988). We expect more females and a higher proportion of females to result in more female participation.

Second, coder/observers recorded the sex of the committee chair who presided over turn-taking and controlled recognition of individual speakers. Research suggests that female chairs may adopt a style of leadership that encourages participation by other females (Kathlene 1995).

Third, committee environments are a key independent variable. The MUNSW offered students an opportunity to select from among five committees: Human Rights (HR), Special Political (SP), Crime and Criminal Justice (CCJ), International Security and Disarmament (ISD), and the Security Council. In later rounds of deliberation, larger assemblies include General Assembly (formed from SP and 
ISD) and Economic and Social Commission or ECOSOC (formed from HR and CCJ). Some committees focused on issues that were distinctively gendered. Therefore, committees were categorized with two dummy variables: masculine issue domains ( $1=$ more masculine, $0=$ other $)$ and feminine issue domains ( $1=$ more feminine, 0 = other). See Table 1 for a summary of issues in the committees' jurisdictions.

Finally, we include a variable to reflect the chair's system of recognizing speakers. Most chairs had no explicit system for this function. By contrast, some rigorously applied a systematic participation rule to the process of recognizing speakers. As explained to committee members in the opening session and reiterated at each committee meeting, for example, the CCJ chair kept track of speaking turns and, when several delegates sought recognition at the same time, called upon the delegate with the lowest number of prior turns. This decision rule had the effect of maximizing opportunities for more hesitant delegates and encouraging more equal participation. We coded 1 for systematic recognition rules, 0 for nonsystematic rules.

We test a logistic regression model to predicttum-taking by females. Controlling for committee size and conference scheduling (first committee session coded 1 and subsequent sessions coded sequentially up to 7 ), we predict that turn s taken by female delegates will be greater when a female is the committee chair, when equal participation opportunities are systematically enforced, when the percentage of females on each committee is greater, and when the issues under discussion are "more feminine." The equation for the logistic regression model predicting speaker sex is:

$$
P_{Y=1}=\frac{e^{a+b_{1} X_{1}+b_{2} X_{2}+b_{3} X_{3}+b_{4} X_{4}+b_{5} X_{5}+b_{6} X_{6}+b_{7} X_{7}}}{1+e^{a+b_{1} X_{1}+b_{2} X_{2}+b_{3} X_{3}+b_{4} X_{4}+b_{5} X_{5}+b_{6} X_{6}+b_{7} X_{7}}}
$$

where: $P_{Y=1}=$ Probability of a Female Speaker

$\mathrm{X}_{1}=$ Female Committee Jurisdiction

$\mathrm{X}_{2}=$ Male Committee Jurisdiction

$\mathrm{X}_{3}=$ Percent Female

$\mathrm{X}_{4}=$ Female Chair

$\mathrm{X}_{5}=$ Committee Size

$\mathrm{X}_{6}=$ Session Number

$\mathrm{X}_{7}=$ Systematic Recognition Rules

To assess the tone of the environment (challenging turns as a percentage of total turns), we use OLS regression. In the 372 events that comprise the conference, about one fourth are situations where delegates refused to yield to questions, therefore events for which the percentage of challenging comments can be calculated total only 252 . We predict that the speaking environment is more likely to be challenging when a male is the committee chair, a higher percentage of delegates are male, and the issues under discussion are "more masculine." Since recognition rules affect who speaks but not what was said, we do not expect this variable to have a significant impact on the tone of the discourse. This model includes the sex of the initial speaker in the event. We expect female speakers to face more challenging behav- ior if they are perceived as less qualified or potentially submissive. On the other hand, Kathlene's research (1995) suggests that males may engage in more challenging interaction with each other. The equation for predicting a challenging speaking environment is presented below.

$$
\begin{gathered}
Y=a+X_{1} b_{1}+X_{2} b_{2}+X_{3} b_{3}+X_{4} b_{4}+X_{5} b_{5}+X_{6} b_{6} \\
+X_{7} b_{7}+X_{8} b_{8}
\end{gathered}
$$

where: $\mathrm{Y}=$ The percentage of non-challenging turns per speaking event

$\mathrm{X}_{1}=$ Female Chair

$\mathrm{X}_{2}=$ Size of the Committee

$\mathrm{X}_{3}=$ Session Number

$\mathrm{X}_{4}=$ Percent Female

$\mathrm{X}_{5}=$ Female Committee Jurisdiction

$\mathrm{X}_{6}=$ Male Committee Jurisdiction

$\mathrm{X}_{7}=$ Systematic Recognition Rules

$\mathrm{X}_{8}=$ Female First Speaker

\section{THE Results}

In spite of the fact that males and females attended the MUNSW in roughly equal numbers and with very similar qualifications, their participation in discourse was anything but equal. Males took more than twice as many turns as females. Table 1 reports the turns taken by female delegate by committee, the ratio of male to female turns coded by committee and chair sex, and the percentage of challenging turns taken. Male delegates took 1409 speaking turns, 67.6 percent of the 2082 turns recorded in committee deliberations. When compared with the overall attendance at the conference, this result would have occurred by chance less than one time in $1000(p<.001)$. The field reports of coder/observers also confirmed the dominance of male turn-taking but also noted the relatively small number of very active female delegates. The vast majority of female delegates participated only minimally if at all, while a larger proportion of males took turns.

In addition, male delegates also spoke first, taking 72.0 percent of first turns (i.e., the initial speech introducing a new resolution, amendment or speaking event), a proportion higher than that of overall turn-taking. T-tests of speaking order reveal that on average male delegates spoke almost one-half turn earlier than female delegates (males, $\bar{X}=4.7$, females, $\bar{X}=5.1, p=.043$ ). In delegations with both male and female members, several coder/observers noted instances of female members deferring to or preparing information for their male colleagues who then spoke on behalf of the delegation.

The role of the chair is critical. While the basic pattern of male dominance was characteristic of all of the MUNSW committees, Table 1 shows that participation varied by committee and by committee chair. In the absence of decision rules to give preference to delegates who were less active or first-time speakers, male chairs on average recognized just over three male turns for each female turn, while on average 
E TABLE 1

Structure, Characteristics, Turns by MUNSW COMmitTeES

\begin{tabular}{|c|c|c|c|c|c|c|}
\hline Committee & $\begin{array}{l}\text { Chair Sex } \\
\text { (\% of Event } \\
\text { Chaired) }\end{array}$ & $\begin{array}{l}\text { \% Females } \\
\text { on } \\
\text { Committee }\end{array}$ & $\begin{array}{l}\% \text { Female } \\
\text { Turns } \\
\text { Taken }\end{array}$ & $\begin{array}{l}\text { Turn Ratio } \\
\text { Male- } \\
\text { Female }\end{array}$ & $\begin{array}{l}\text { Challenging } \\
\text { Turns as } \\
\% \text { of Total }\end{array}$ & $\begin{array}{l}\text { Issue Jurisdiction } \\
\text { of the Committee }\end{array}$ \\
\hline Human Rights & $\begin{array}{l}\text { Male }(23.8 \%) \\
\text { Female }(76.2 \%)\end{array}$ & $\begin{array}{l}47.6 \\
47.6\end{array}$ & $\begin{array}{l}19.0 \\
42.8\end{array}$ & $\begin{array}{l}4.26 \\
1.34\end{array}$ & $\begin{array}{l}39.3 \\
36.2\end{array}$ & $\begin{array}{l}\text { more feminine issues } \\
\text { children, minorities \& women's } \\
\text { rights, population control }\end{array}$ \\
\hline Int. Security \& & Male $(20.8 \%)$ & 40.4 & 15.7 & 5.37 & 77.8 & more masculine issues \\
\hline Disarmament (ISD) & Female $(79.2 \%)$ & 40.4 & 24.2 & 3.13 & 48.5 & $\begin{array}{l}\text { weapons control, nuclear } \\
\text { proliferation, border disputes }\end{array}$ \\
\hline Crime \& Criminal & Male (100\%) & 53.7 & 51.5 & 0.94 & 53.4 & $\begin{array}{l}\text { mix of issues } \\
\text { industrial espionage, organized }\end{array}$ \\
\hline Justice (CCJ) & & & & & & crime, drugs \\
\hline Security Council (SC) & Female (100\%) & 33.5 & 28.1 & 2.56 & 38.6 & $\begin{array}{l}\text { more masculine issues } \\
\text { terrorism, geopolitical crises, } \\
\text { armed conflicts }\end{array}$ \\
\hline Special Political (SP) & Male (100\%) & 43.5 & 20.1 & 3.98 & 56.2 & $\begin{array}{l}\text { mix of issues } \\
\text { trade, internet, NGOs } \\
\text { environment, elections }\end{array}$ \\
\hline Gen. Assembly (GA) & Male (100\%) & 45.5 & 23.5 & 3.26 & 47.0 & $\begin{array}{l}\text { more masculine issues } \\
\text { combines ISD, SP }\end{array}$ \\
\hline ECOSOC & Female (100\%) & 66.9 & 45.8 & 1.18 & 39.4 & $\begin{array}{l}\text { more feminine issues } \\
\text { combines HR, CCJ }\end{array}$ \\
\hline
\end{tabular}

female chairs recognized 1.67 male turns for each female turn. This difference in ratios would have a probability of occurring by chance of less than one time in a thousand. In the SP Committee, the coders reported a period of almost 90 minutes during which no female was recognized by the male chair even though several female delegates raised their hands for recognition. The male CCJ committee chair was the most egalitarian giving preference to less active delegates over more assertive and active delegates.

The dominant speaking style at the MUNSW is challenging. Challenging turns constitute 48.3 percent of all turns taken, while non-challenging turns total 32.0 percent of the turns, and other turns comprise the balance (19.7 percent). Table 1 also shows the proportion of challenging turns varied by chair and committee.

Turning to the data on questioning, surprisingly we did not find the delegates treating female speakers differently from male speakers. When the dependent variable measures questions or interruptions received by each speaker, the analysis shows that these are directed with almost identical frequency toward males and females. In t-tests, questions received by speakers are almost identical (female speakers $\bar{X}$ $=6.00$, males $\bar{X}=6.07, p>.05$ ). It appears the delegates did not alter their behavior based on whether the initial speaker was a female. Predicting Turns-Taking and Type of Speaking

\section{Environment}

Table 2 reports the logistic regression results. As expected, the jurisdiction of the committee is significantly associated with female turn-taking. The slope coefficient is in the predicted direction with feminine issue committees fostering greater female participation. The odds of a female taking a turn in the female committees are 1.55 times greater than in other committees. ${ }^{3}$ Secondly, a female chair presiding over the committee is significantly and positively associated with female turn-taking. Controlling for the other variables in the equation, the odds that a female chair will call on a female speaker are 2.22 times greater than are those for a male chair. Having a systematic recognition rule that grants less active speakers an opportunity to speak increases the odds for a female speaker by 5.47 times. The final significant association involves committee size. Females are more likely to take turns in larger committees presumably because there are simply more females present. Surprisingly, the percentage of females on the committee has almost no effect on the likelihood that a female will speak.

Table 3 presents the findings of the second model, where the percentage of challenging turns taken during each speaking event is the dependent variable. Though the model explains only 12 percent of the variance, some factors are highly significant and in predicted directions. The strongest predictor of a more challenging environment (i.e., more disagreeing, attacking, and proposing challenging questions) is the sex of the chair. The presence of a female chair decreases the predicted percentage of challenging turns per speaking

\footnotetext{
3 The exp (b) can be interpreted as the predicted change in the odds of a female speaker as the predictor increases by one unit. For a dichotomous p redictor (e.g., chair sex), the exp (b) conveys the difference in the predicted odds of a female speaker between the two coding categories.
} 
$\equiv$ TABLE 2

Logistic Regression Estimates Predicting Female Turn-Taking

\begin{tabular}{lrlr}
\hline Variables & \multicolumn{1}{c}{$\mathrm{b}$} & \multicolumn{1}{c}{ s.e. } & exp (b) \\
\hline $\begin{array}{l}\text { Constant } \\
\text { Female Committee }\end{array}$ & -2.090 & $(.308) * * *$ & \\
$\quad$ Jurisdiction & .438 & $(.233)^{*}$ & 1.549 \\
Male Committee & & & \\
$\quad$ Jurisdiction & -.212 & $(.196)$ & .809 \\
Percent Female & .005 & $(.006)$ & 1.005 \\
Female Chair & .798 & $(.188)^{* * *}$ & 2.217 \\
Committee Size & .004 & $(.002)^{* *}$ & 1.004 \\
Session Number & .019 & $(.029)$ & 1.019 \\
Systematic Rules & 1.699 & $(.232)^{* * *}$ & 5.467 \\
Log-likelihood & 2403.921 & & \\
Null Prediction & $68.1 \%$ & & \\
\% Correct Prediction & $69.0 \%$ & & \\
Cox and Snell R ${ }^{2}$ & .068 & & \\
Nagelkerke R ${ }^{2}$ & .095 & & \\
Valid N & 2034 & & \\
\hline
\end{tabular}

${ }^{*} \mathrm{p}<.05 ;{ }^{*} \mathrm{p}<.01 ;{ }^{* * *} \mathrm{p}<.001$, one-tailed test.

$\equiv$ TABLE 3

OLS Regression Estimates Predicting a Challenging SPEAKING ENVIRONMENT

\begin{tabular}{lcc}
\hline Variables & $\mathrm{b}$ & \multicolumn{1}{c}{ s.e. } \\
\hline Constant & $63.057^{* * *}$ & $(10.020)$ \\
Female Chair & $-15.007^{* * *}$ & $(4.612)$ \\
Size of the Committee & .051 & $(.047)$ \\
Session Number & -1.099 & $(.872)$ \\
Percent Female & $-.392^{*}$ & $(.168)$ \\
Female Committee Jurisdiction & 5.057 & $(4.308)$ \\
Male Committee Jurisdiction & .271 & $(4.276)$ \\
Systematic Rules & -1.129 & $(5.504)$ \\
Female First Speaker & -.211 & $(3.676)$ \\
Adj. R & & .121 \\
$\mathrm{~N}$ & & 252 \\
$\mathrm{~F}$ & & $5.324 * * *$ \\
\hline
\end{tabular}

${ }^{*}$ p $.05,{ }^{* *}$ p $.01,{ }^{* * *}$ p .001 .

event by more than 15 percent. The percentage of females on the committee is also statistically significant and contributes to a less challenging environment; as the share of female delegates increases by one percent, challenging turns decrease by about .4 percent. Contrary to expectations, committee jurisdiction does not have a significant effect and in fact challenging turns as a percentage of speaking events increase by more than 5 percent in the feminine issue committees. Most surprising, the sex of the speaker who initiates a speaking event appears to have no effect. Female speakers precipitate slightly fewer challenging turns but the effect is not significant. The relationship between the session's timing and the speaking environment is modestly negative $(p>.05)$, indi- cating that as the conference moved into later sessions the debate became less challenging.

In sum, political discourse is clearly shaped by context, but a key feature-equal proportions of male and female delegates-does not insure equal turn-taking. The proportion of female delegates does, however, reduce the challenging tone of the discourse. The context does shape opportunities for participation. Female turn-taking increases when the issue jurisdiction focuses on more feminine issues and when the committee is chaired by a female. A female chair also is strongly associated with less challenging debate.

\section{Discussion AND CONCLUSION}

What explains the lower levels of female participation? Does this analysis simply document typical adolescent behavior, point to gendered institutional dynamics, or perhaps reflect a regional pattern of gendered behavior? We consider each of these explanations in turn.

First, the lower overall levels of female participation and the highly deferential behavior of some MUNSW female delegates might be due to norms of adolescent behavior. The findings suggesting tentativeness are consistent with Mahoney's (1985) research on classroom behavior, which finds that boys communicate ownership of school space by using aggressive or disruptive behavior. As a result of the aggressive classroom climate, Mahoney reports that girls often prefer not to participate in classroom discussions. Similarly, the dominance of aggressive and challenging behavior, particularly in the early stages of the MUNSW, may have worked to discourage female participation. But adolescent gender norms cannot explain our data with respect to interruptions and challenges. Unexpectedly, our data show that male and female MUNSW delegates do not discriminate among whom they engage. Delegates interrupt and challenge each other to a similar degree, thus suggesting that delegates generally accord male and female speakers similar status and respect. These results contradict research by Kathlene (1995) who noted that aggressive turn-taking men challenged men more often than women and thus treated women as intruders into an essentially male domain. Clearly more research is needed to unravel assumptions about status and competence in discourse engagement and interaction, but our results cannot be explained solely by adolescent behavior.

Second, our research confirms that the institutional context matters, but one important variable - the percentage of females on each committee-matters less than had been expected. Many male MUNSW chairs failed to incorporate female delegates equitably in debate, and girls who did want to participate encountered greater difficulty getting speaking time when committees dealt with issues that may be construed as more masculine. The simulation produces discourse that contains significant inequalities even though the circumstances of the event-balanced proportions of females to males and similar qualifications of the delegates-would portend favorable and equitable participation. 
While our analysis suggests that having a certain number of women may be a necessary but not sufficient condition for women's political participation, we do conclude that the presence of women's voices alters the degree to which norms of masculinity prevail. The percentage of female delegates and the role of female chairs appear to contribute to a less challenging speaking environment, but the impact is not great. In the end, institutional context matters but does not fully explain participation.

Third, the discourse may reflect regionally rooted behaviors and norms. We discount this interpretation for two main reasons. Most impoitantly, the discourse at MUNSW reveals patterns very similar to that found by scholars who look at gendered discourse in state legislatu res (Kathlene 1994), the U.S. Congress (Mattei 1998), or among a national sample of public administrationists and academicians (Hale 1999). Indeed, these results suggest that politically minded male adolescents behave much like the men in Kathlene's (1994) study of Colorado legislative committee hearings: Men engaged immediately and spoke longer, while women on average, spoke fewer words and waited until more than two-thirds of the hearing was over before they uttered their first words. We also doubt the significance of regional behavioral norms because most MUN delegates self-select to attend the event, and we fathom no reason to believe that equally qualified adolescents would chose to attend an event and then opt to sit on the sidelines.

In the final analysis, we conclude that these results demonstrate adolescent expectations and perceptions about politics as a masculine domain. The fact that these simulations are role plays enacted over a short period of time means that institutional norms are weak. While these events mimic legislative processes, they lack Polsby's (1968) notion of boundedness, a concept suggesting that institutions are differentiated from their environments, have stable membership, and relatively difficult rules of entry. We speculate, therefore, that these events are shaped not only by institutional factors but also by gendered expectations about political institutions.

Several findings are most important to this conclusion. One particularly telling incident suggests that female delegates perceive that they are clearly operating on masculine turf: Several females delegates during one session wore men's suit jackets and ties, suggesting that they perceived male business attire to be the norm for such events. The type of turns taken at the MUNSW also suggests that both male and female delegates adopt challenging speaking behavior as the norm, and we suspect that tentativeness and lack of turn-taking are manifestations of doubts by some adolescent females about whether they are qualified for or comfortable with these more masculine styles of political leadership. As Kenney (1997: 456) notes, political institutions "produce, reproduce and subvert" gender in their processes and arrangements of power, and certainly interaction styles get inscribed later as the dominant modes of leadership among adult political leaders including state legislative committee chairs (Rosenthal 1998). New research also shows that women in legislatures can become disenchanted with the aggressive norms of masculine parliamentary conduct (Broughton 2000).

In sum, masculinity in political discourse is already well established and dominant in adolescent extracurriculars even when those events draw equally qualified and similar numbers of males and females. Whatever the source of discourse inequities, these results give us pause in our optimism that greater representation by women in an institution necessarily leads to equality of participation. Simply increasing the number of women participating in the discourse is not enough to ensure the representation of women's interests. For feminists who wish to cultivate future women political leaders, the implications are clear: Even the most well-intended learning experiences may be teaching future generations of women that politics is still a masculine domain. If adolescents already hold gendered assumptions about the political sphere, then as Kenney (1995: 461) predicts, ". . . the continued gendering of institutions will reinscribe notions of gender that lead to women's subordination."

\section{REFERENCES}

Broughton, Sharon. 2000. "Leadership is a Feminist Issue: Do Women in the Australian Parliament Make a Difference?" Ph.D. Dissertation, Department of Government, University of Queensland.

Drass, K. A. 1986. "The Effect of Gender Identity on Conversation. Social Psychology Quarterly 49: 294-301.

Edelsky, Carole. 1993. "Who's Got the Floor?" In Deborah Tannen.,ed., Gender and Conversational Interaction, New York: Oxford University Press.

Hale, Mary. 1999. "He Says, She Says: Gender and Worklife," Public Administration Review 59: 5, 410-24.

James, D., and J. Drakich. 1993. "Understanding Gender Differences in Amount of Talk: A Critical Review of Research." In Deborah Tannen, ed., Gender and Conversational Interaction. New York: Oxford University Press.

Kanter, R. M. 1977. Men and Women of the Corporation. New York: Basic Books.

Kathlene, L. 1994. "Power and Influence in State Legislative Policy Making: The Interaction of Gender and Power in Committee Hearing Debates." American Political Science Review 88 (3): 560-76.

1995. "Position Power Verses Gender Power: Who Holds the Floor?" In G. Duerst-Lahti and R. M. Kelly, eds., Gender Power, Leadership, and Governance. Ann Arbor: University of Michigan Press.

Kenney, S. 1997. "New Research on Gendered Political Institutions." Political Research Quarterly 49 (2): 445-66.

Kollock, P., P. Blumstein, and P. Schwartz. 1985. "Sex and Power in Interaction." American Sociological Review, 50: 34-47.

Lakoff, R. T. 1990. Talking Power: The Politics of Language in Our Lives. New York: Basic Books.

Leet-Pellegrini, H. M. 1980. "Conversational Dominance as a Function of Gender and Expertise." In H. Giles, W. P. Robinson, and P. M. Smith, eds.,. Language: Social Psychological Perspectives, Oxford: Pergamon. 
Levy, Dana, Charles Tien, and rachelle Aved. 20001. "Do Differences Matter? Women Members of Congress and the Hyde Amendment." Women \& Politics 23 (1/2): 104-28.

Mahoney, P. 1985. Schools for the Boys? Co-education Re-assessed. London: Hutchinson Publishing Group.

Mattei, L. W. 1998. "Gender and Power in American Legislative Discourse." Journal of Politics 60 (2): 440- 61.

Pitkin, Hanna Fenichel. 1967. The Concept of Representation. Berkeley: University of California Press.

Polsby, Nelson W. 1968. "The Institutionalization of the U.S. House of Representatives," American Political Science Review 62: 44-68.

Ridgeway, C., and J. Johnson. 1990. "What is the Relationship Between Socioemotional Behavior and Status in Task Groups?' American Journal of Sociology 95: 1189-1212.

Rosenthal, Cindy Simon. 1998. When Women Lead. New York: Oxford University Press.

Schlozman, K. L., N. Burns, S.Verba, and J. Donahue. 1995. "Gender and Citizen Participation: Is There a Different Voice?" American Journal of Political Science 39 (2): 267-93.

Smith-Lovin, Lynn, and Charles Brody. 1989. "Interruptions in Group Discussions: the Effects of Gender and Group Composition." American Sociological review 54: 424-35

Smith-Lovin, Lynn, and D. T. Robinson. 1992. "Gender and Conversational Dynamics." In Cecilia L. Ridgeway, ed., Gender, Interaction, and Inequality. New York: Springer-Verlag.
Sigel, Roberta S. 1989. Political Learning in Adulthood: A Sourcebook of Theory and Research. Chicago: University of Chicago Press.

Swann, J. 1988. "Talk Control: An Illustration from the Classroom of Problems in Analyzing Male Dominance of Conversation." In Jennifer Coates and Deborah Cameron, eds., Women in Their Speech Communities. London: Longman.

Tamerius, K. L. 1995. "Sex, Gender, and Leadership in the Representation of Women." In Georgia Duerst-Lahti and Rita Mae Kelly, eds., Gender Power, Leadership, and Governanc,. Ann Arbor: University of Michigan Press.

Verba, S., K. L. Schlozman, and H. E. Brady. 1995. Voice and Equality: Civic Voluntarism in American Politics. Cambridge, MA: Harvard University Press.

Walsh, Katherine Cramer. 2002. "Enlarging Representation: Women Bringing Marginalized Perspectives to Floor Debate in the House of Representatives." In Cindy Simon Rosenthal, ed., Women Transforming Congress. Norman: University of Oklahoma Press.

Zimmerman, Don H., and Candace West. 1975. "Sex Roles, Interruptions, and Silences in Conversation." In Barrie Thorne and Nancy Henly, eds., Language and Sex: Difference and Dominance. Rowley, MA: Newbury House.

csrosenthal@ou.edu 